\title{
Intensive care of the surgical thoracic patient
}

\author{
Olof P. NORlander INGRID NordéN

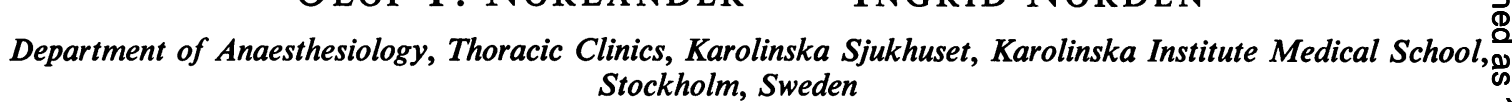

OUR intensive care unit of eight to twelve beds takes in patients from a unit of eighty surgical thoracic beds that serves a population of 1.5 million. Approximately 1500 major thoracic surgical procedures, including 150-200 open heart operations, are performed each year. This unit functioned from 1958 to 1965 in a slightly modified general thoracic surgical ward but since last year has been housed in a specially designed area that permits isolation, reduces the risk of cross-infection to a minimum and makes working conditions for personnel as attractive as possible (Fig. 1). The unit has a small recovery area with three beds for the care of outpatients undergoing diagnostic procedures such as mediastinoscopies and angiocardiograms, and is situated on the same floor as the operating theatres. The main intensive care unit has two single-bedded rooms suitable for the treatment of isolation cases according to fever hospital principles, two more fully equipped rooms of two beds each and two recovery areas, each with two beds. The first four rooms have facilities for disposal or decontamination of soiled articles and connections for an artificial kidney. Large transparent windows set into the dividing walls of these rooms enable the staff to observe their colleagues in the adjacent rooms and this reduces their sense of isolation. The standard equipment available (Fig. 2) includes closed circuit television, an intercommunications system and a special alarm system that is independent of the general hospital telephone system. As is apparent from Fig. 1, fully half the unit is 'ancillary space' housing a blood-gas laboratory with full-time technicians, duty officers' and personnel rest room. The entire ward is air-conditioned and is staffed by a permanent complement of fifteen certified nurses, six nurse assistants, fourteen technicians, three orderlies and some extra technicians (total staff of about fifty people) working a shift system. The hospital authorities run a special course for the intensive care unit staff.

\section{Respiratory problems}

Long-standing pulmonary disease that reduces respiratory reserve, and post-operative complications such as atelectasis, retained bronchial secretions and intrathoracic fluid accumulation often result in post-operative hypoxia or respiratory acidosis that can be tolerated by a healthy subjecto but not by the high-risk patients that we treat 3 . Early detection of these disorders by clinical means is usually not possible and we have found it necessary and worthwhile to measure arterial oxygen tensionso and saturation, arterial carbon dioxide and $\mathrm{pH}$ andī measure respiratory work. Crafoord (1938) sug- $\infty$ gested that increased respiratory work in these음 circumstances may contribute to respiratory and circulatory failure, and further studies (Bjork \& Engström, 1955; Damman et al., 1963; Grenvik, 1966) which have contributed to this view are substantiated $\vec{c}$ by oxygen uptake measurements during spontaneous $\mathrm{V}$ and controlled ventilation (Engström, Herzog \& Norlander, 1961), especially in cardiac failure following open-heart procedures (Figs. 3 and 4) when oxygen consumption may be reduced from $13 \%$ to $50 \%$ when mechanical ventilation replaces spon- $\frac{\AA}{\Phi}$ taneous respiration.

\section{Respiratory care}

When lung function is impaired, or cardiac failure or a greatly increased heart-size $\left(>600 \mathrm{~cm}^{2} \stackrel{-}{.}\right.$ $\mathrm{m}^{2}$ ) is present, it is routine to follow arterial blood-을 gases during the anaesthesia and immediately after.:If $\mathrm{PaO}_{2}$ decreases during anaesthesia in spite of high concentrations of inspired oxygen $\left(\mathrm{PaO}_{2}<80 \mathrm{mmHg}\right)$, the endotracheal tube is usually kept in place after the operation and the patient is transferred to the ${ }_{0}$ intensive care unit and connected to an Engström? respirator. The estimation of pulmonary function, and the degree of right-to-left shunting during anaesthesia and post-operatively, is facilitated byor the use of the Engström machine for the administra- N tion of ventilation and volatile anaesthetics as it N allows any mixture of oxygen with room air and $\sigma$ nitrous oxide. The shunts may be approximately estimated by the use of the following formula:

$$
\frac{\mathrm{Q}}{\mathrm{Qs}}=\frac{\mathrm{PAo}_{2}-\mathrm{PaO}_{2}}{1+\frac{(\mathrm{A}-\mathrm{V} \text { diff }) \times 330}{\mathrm{PAO}_{2}-\mathrm{PaO}_{2}}}
$$

assuming a $\mathrm{PaO}_{2}>150 \mathrm{mmHg}$ (Gordh, Linderholm $\stackrel{\mathrm{\Phi}}{\mathrm{D}}$ \& Norlander, 1958). Thus in thirteen patients with open valve repairs the pulmonary shunting increased from $3.8 \%$ (range $0 \cdot 7-9.0 \%$ ) preoperatively to $12.8 \%$ 


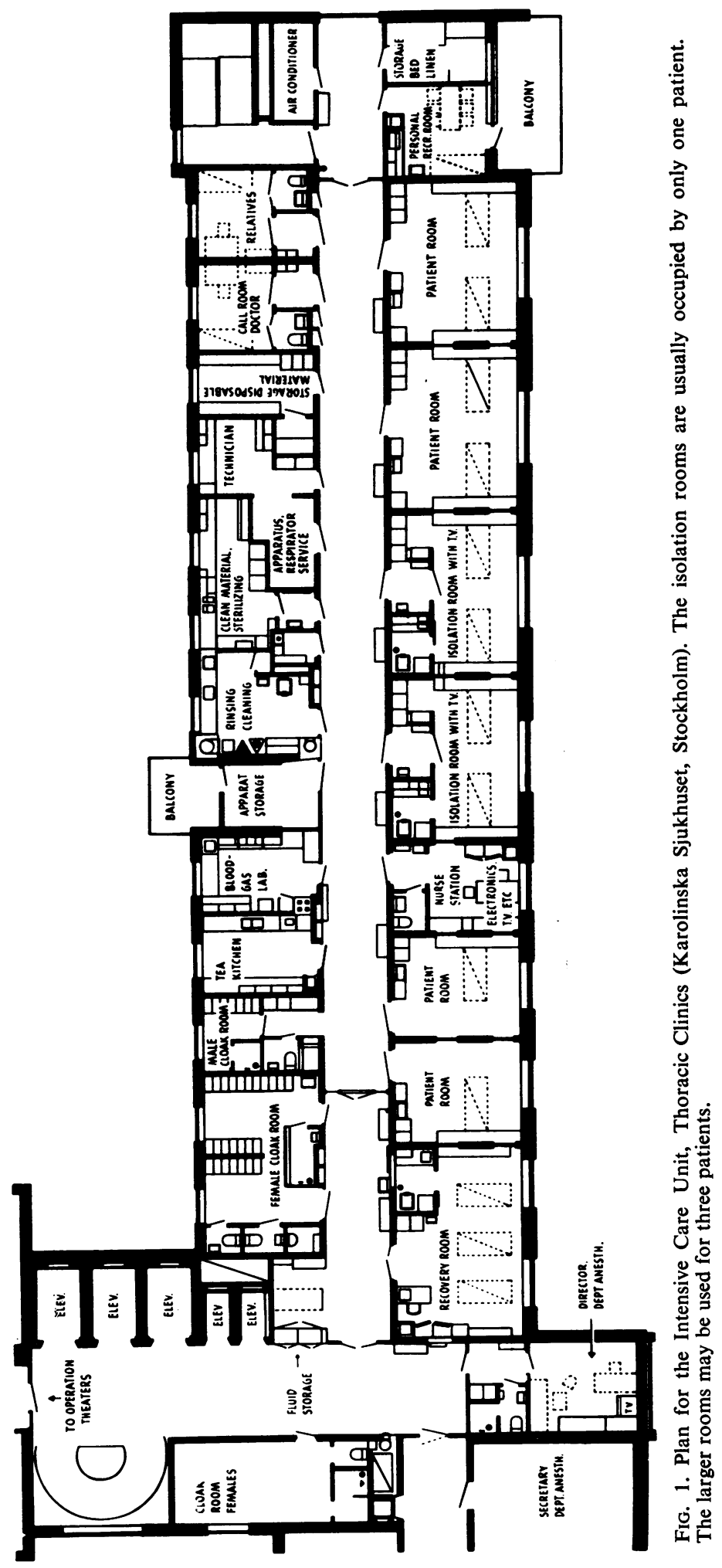




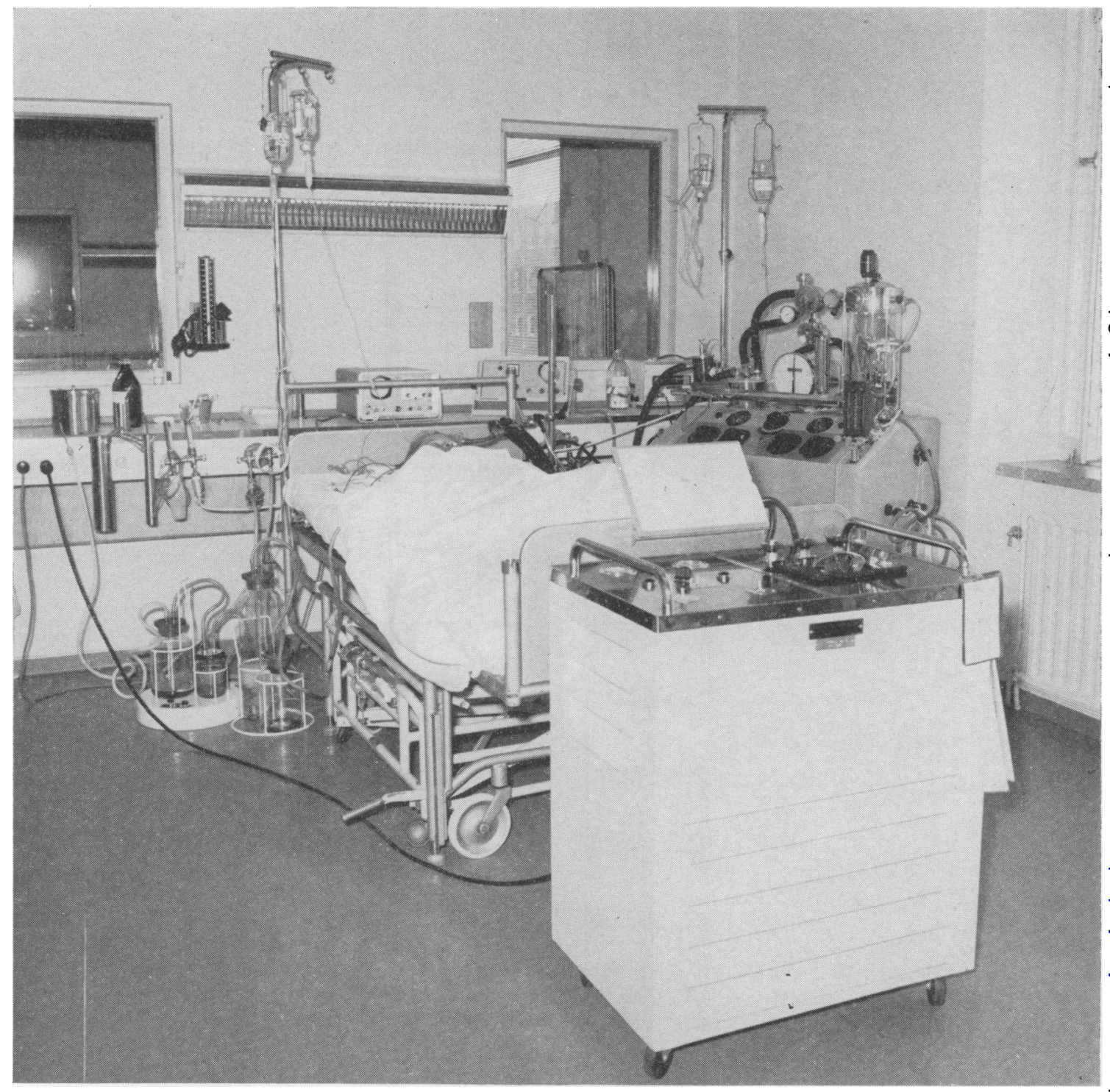

FIG. 2. Intensive care treatment after heart surgery. Note the bench with contacts for electricity, outlets for oxygen and compressed air (Venturi suction), stainless steel rack for catheter receptors and containers. The bench encloses all leads $\mathrm{G}$ and is easy to clean on all surfaces. The intensity of light source behind the bed can be regulated and ensures a correct colour reproduction. On the bench capillary pulse monitor, ECG and arterial pressure monitor. The Engström respirator in the corner and cooling device at the front of the bed.

(range $3 \cdot 1-20 \cdot 9 \%$ ) of systemic output post-operatively immediately after the end of surgery (Thung \& Norlander, 1966) (Table 1).

Due to the favourable gas-flow characteristics of the Engström respirator and its mode of operation (Engström, 1963), the synchronization of the patients with the machine has not been a problem and muscle relaxants have not been used for this purpose. Morphine, pethidine and phenoperidine-chloride in small doses intravenously are used in combination with about $10-20 \%$ nitrous oxide in the inspired gas mixture for patients with an endotracheal tube. Oxygen concentrations of inspired gas are usually $50-60 \%\left(50 \% \mathrm{O}_{2}+50 \%\right.$ room air $)$. With this procedure the patients tolerate an endotracheal tube surprisingly well. In adults the tube is usually kept for 24-48 hr. If longer periods of controlled ventilation are then deemed necessary a tracheotomy is 8 
performed. Plastic, single lumen tracheotomy tubes (Portex) with glued-on rubber cuffs (Eynard) are used and usually changed once a week. The patients are followed by blood-gas analysis during the critical or acute phases, but otherwise the respirator treatment is mainly managed on the basis of clinical which adapts itself to the impedance of the lungs. Even relatively large differences in time constant within the lungs do not create uneven distribution of the tidal volume (Sabar et al., 1965). The static or no-flow period at the end of each inspiratory period allows us to draw conclusions from the changes in

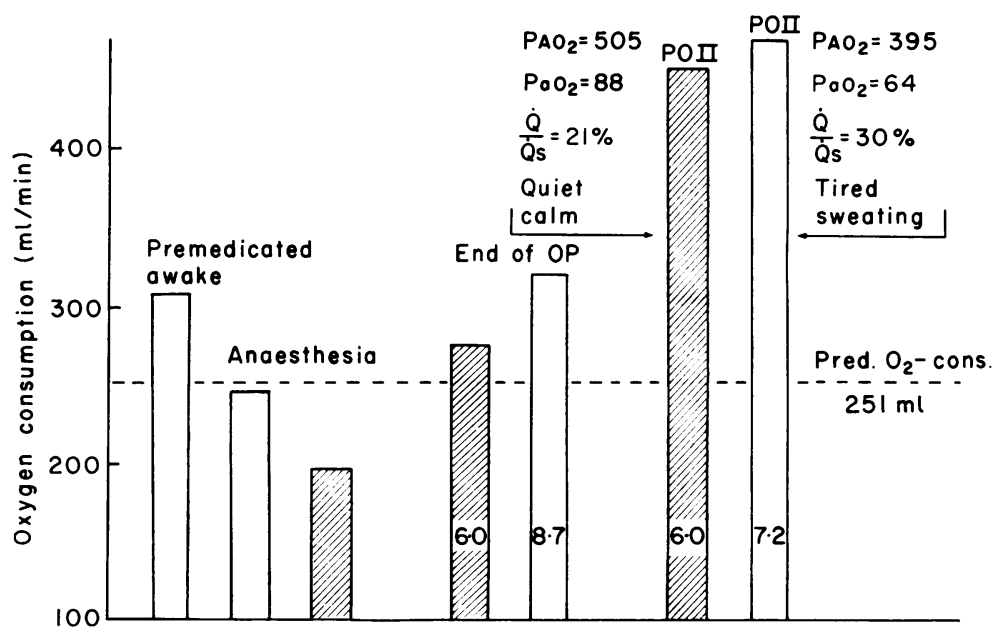

FIG. 3. Increase in oxygen uptake post-operatively. Observe the increase in cardiac output associated with spontaneous respiration at end of operation. Female, 40 years-A.S. Starr valve. Cross-hatched columns, respirator; unshaded columns, spontaneous. (Figures on columns are those for cardiac output.)

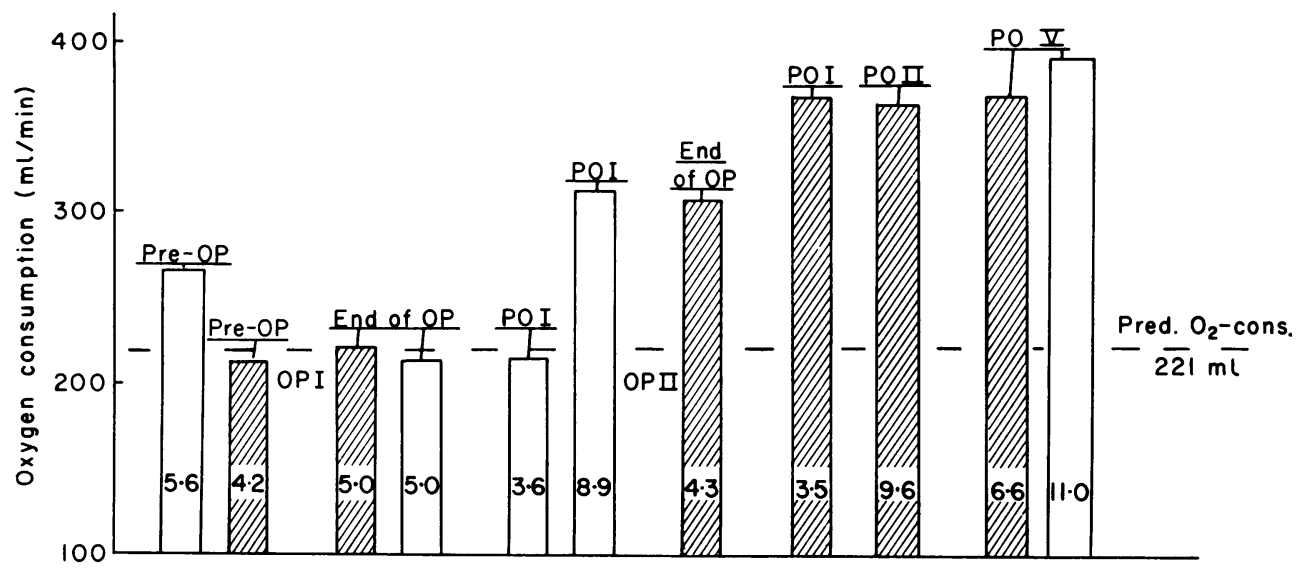

FIG. 4. Continuous increase in oxygen uptake following re-operation after aortic valvular procedure. At OP I acute aortic valvular insufficiency occurred which necessitated a ball-valve prothesis at OP II. Male, 43 years-A.S. Cross-hatched columns, respirator; unshaded columns, spontaneous.

observations and experience. The ventilatory volumes being returned from the patient are followed at regular intervals as well as peak (dynamic) air-way pressures and end-tidal volume pressures (compliance pressure). Those values give us valuable information about the conditions of lung and circulation as they allow estimation of air-way resistance and elasticity conditions of the lung and chest. The respirator administers the tidal volume with a gas-flow pattern compliance, a clinically most important observation with reference to left-auricular pressure and the development of pulmonary oedema. Negative pressures during the expiratory phase are practically never used and no need has been found for frequent deep sighs from the respirator as based on blood-gas analysis. The respiratory frequency is usually around $18-20 / \mathrm{min}$ and the ventilatory volumes around $8-141 / \mathrm{min}$, depending on the size of the 
TABLE 1

Pulmonary shunting during and after open-heart surgery (Thung \& Norlander, 1966)

\begin{tabular}{|c|c|c|c|c|c|c|c|c|}
\hline $\begin{array}{l}\text { Patient } \\
\text { No. }\end{array}$ & Diagnosis & I & II & III & IV & $\mathbf{V}$ & VI & VII \\
\hline $\begin{array}{r}2 \\
9 \\
12 \\
13 \\
18 \\
20 \\
28 \\
52 \\
58 \\
60 \\
61 \\
64\end{array}$ & $\begin{array}{l}\text { AS } \\
\text { AI } \\
\text { AS } \\
\text { AS } \\
\text { AS } \\
\text { MI } \\
\text { MI } \\
\text { MI } \\
\text { AI } \\
\text { AS } \\
\text { AS } \\
\text { AI } \\
\text { AS }\end{array}$ & 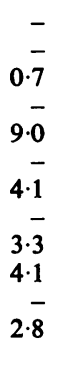 & $\begin{array}{r}6.5 \\
4.5 \\
2.2 \\
5.8 \\
19 \cdot 2 \\
2.8 \\
- \\
5 \cdot 7 \\
9.7 \\
12.6 \\
23.4 \\
11 \cdot 1\end{array}$ & $\begin{array}{l}15.9 \\
10 \cdot 8 \\
18 \cdot 6 \\
18 \cdot 5 \\
14.5 \\
16 \cdot 1 \\
14 \\
16.7 \\
12.9 \\
13.4 \\
15.3 \\
18.6\end{array}$ & $\begin{array}{l}19 \cdot 5 \\
12 \cdot 4 \\
14 \cdot 9 \\
18 \cdot 1 \\
- \\
18.9 \\
34 \\
13 \cdot 1 \\
10 \cdot 6 \\
15 \cdot 1 \\
24 \cdot 2 \\
18 \cdot 7\end{array}$ & $\begin{array}{r}13 \cdot 9 \\
8 \cdot 6 \\
12 \cdot 6 \\
25 \cdot 7 \\
17 \cdot 3 \\
33 \cdot 6 \\
53 \\
25 \cdot 6 \\
12 \cdot 5 \\
17 \cdot 5 \\
27 \cdot 3 \\
17 \cdot 2\end{array}$ & $\begin{array}{l}10 \cdot 5 \\
12 \cdot 6 \\
15 \\
15 \cdot 5 \\
18 \cdot 6 \\
13 \cdot 2 \\
12 \\
23 \cdot 6 \\
12 \cdot 7 \\
16 \cdot 3 \\
21 \cdot 7 \\
13 \cdot 8\end{array}$ & $\begin{array}{r}5.3 \\
11.8 \\
\\
3.1 \\
15.7 \\
12.9 \\
\overline{-} \\
13.5 \\
\overline{-} \\
13.5 \\
10.6 \\
11.6\end{array}$ \\
\hline 66 & $\begin{array}{l}\text { MI } \\
\text { AI }\end{array}$ & $2 \cdot 5$ & $9 \cdot 9$ & $23 \cdot 4$ & 26 & 36 & $17 \cdot 1$ & 20.9 \\
\hline $\bar{x}$ & & 3.8 & $9 \cdot 5$ & $16 \cdot 1$ & $18 \cdot 8$ & 23.0 & $15 \cdot 6$ & $12 \cdot 8$ \\
\hline Range & & $\begin{array}{l}0.7- \\
9 \cdot 0\end{array}$ & $\begin{array}{c}2 \cdot 2- \\
23 \cdot 4\end{array}$ & $\begin{array}{l}10 \cdot 8- \\
23 \cdot 4\end{array}$ & $\begin{array}{l}10 \cdot 6- \\
34.0\end{array}$ & $\begin{array}{c}8.6- \\
53.0\end{array}$ & $\begin{array}{l}10 \cdot 5- \\
23 \cdot 6\end{array}$ & $\begin{array}{r}3 \cdot 1 \\
20.9\end{array}$ \\
\hline
\end{tabular}

patient. The actual amount of ventilation to be set at the respirator is usually higher than those values obtained from calculation of ventilation from the nomogram (Engström \& Herzog, 1959). This is explained by an increased metabolism and an increased dead-space/tidal-volume ratio (Freeman \& Nunn, 1963; Hedley-Whyte et al., 1965; Grenvik, 1966; Thung \& Norlander, 1966). The Engström respirator has been used for more than 10 years in our service. All categories of personnel have a thorough knowledge of its use and management. This adds to the safety of the treatment and is a guarantee that technical mistakes are not made.

\section{Humidification}

Adequate humidification is assured by the use of an ultrasonic nebulizer in the respiratory circuit. This device, introduced for respirator treatment in our clinic in 1962 has a capacity of humidification with aerosol particles of $0 \cdot 8-1.0 \mu$ with a relative humidity of over $100 \%$ at $37^{\circ}$ with oxygen at ventilatory volumes of over $20 \mathrm{1} / \mathrm{min}$ (Herzog, Engström \& Norlander, 1964). The generator equipment is now automatically tuned to a constant ultrasonic frequency of 3 megacycles and needs very little attention. Distilled water is usually used for humidification, but favourable results have been obtained with physiological saline with the addition of bronchodilators such as isoproterenol sulphate. The amount of the drug delivered by the nebulizer depends on drip rate to the nebulizer head and the ventilation of the patient and may be calculated from the humidification nomogram of the ultrasonic device. With a drop rate of $6 / \mathrm{min}$ and a $0.05 \%$ isoproterenol solution, about $0.0075 \mathrm{mg}$ of the drug is administered to the lungs per breath, which is considered sufficient for relief of an asthmatic attack. If continuous administration is required, a $0.01 \%$ solution may be sufficient (Gay \& Long, 1949).

\section{Control of circulation and acid-base balance}

A number of factors may contribute to a failing circulation post-operatively and here only some of $\overrightarrow{\vec{O}}$ the variables which we try to follow are detailed. All patients with an unsatisfactory circulation, or where such is expected to develop, have their central venous pressures monitored through a to catheter placed in the right auricle or superior vena cava. In patients with an open chest operation this may be done by the surgeons during the operation by the special technique described by Björk \& Grenvik (1967).

Peripheral arterial pressure is monitored from an indwelling radial artery catheter placed percutane- $\rightarrow$ ously. ECG and sometimes peripheral capillary pulse flow are monitored. The treatment of hypotension $N$ and shock is carried out according to surgical and cardiophysiologic principles. Blood-losses are care- O fully measured and replaced. Haematocrit and haemo- $\omega$ globin values are followed as well as chest- and/or abdominal radiographs. Digitalis is commonly used $\varrho$ in patients over 50 years of age after major thoracic surgery and the dose administered is supervised by a special cardiologist.

Urinary output is followed hour by hour in all open-heart patients and also in those who have pre-operative signs of impaired renal function. In $\stackrel{\mathbb{Q}}{\varrho}$ cases of oliguria not due to inadequate fluid-replacement, the patients are immediately treated with 
hypertonic $(40 \%)$ glucose solutions and concentrated human albumin according to the principles advocated by renal units. If haemodialysis is necessary a Kolff artificial kidney is available on the premises.

\section{Bleeding problems}

One of the most common post-operative complications in surgery, especially in heart-lung surgery, is excessive bleeding. The bleeding can have a diverse etiology such as (1) inadequate mechanical haemostasis, (2) defective vascular haemostasis, (3) fibrinolysis, (4) other defects in the coagulation mechanism, and (5) in connection with extracorporeal circulation, inadequately neutralized heparin.

Many cases of mechanical haemostasis defects are difficult to diagnose without the analysis of the coagulation status. In the coagulation defects causing bleeding a complete or at least partial coagulation analysis is necessary.

The most important coagulation assays, in addition to the counting of platelets, are the coagulation time and the thrombin generation test. Furthermore, the determination in plasma of the recalcification time and the content of heparin, Factor V, prothrombin + proconvertin, and fibrinogen as well as the determination of fibrinolytic activity, is important.

If normal values are found, a mechanical defect must first be considered and immediate surgical intervention is indicated. The heparin assay will show if a prolonged coagulation time, recalcification time, a decreased Factor $\mathbf{V}$ and $\mathbf{P} \times \mathbf{P}$ level might be due to remaining heparin or to a consumption of the coagulation factors. Heparin is neutralized by protamine dichloride, which is preferred to protamine sulphate. After protamine sulphate heparin rebound is said to be found but this is not the case when using protamine chloride. Fibrinolysis is treated with kallikrein inhibitor (Trasylol) or epsilonaminocaproic acid (Epsikapron). Fibrinogen deficiency is treated with fibrinogen concentrates prepared if possible from small batches of blood in order to decrease the risk of serum-hepatitis as much as possible.

Decreased content of coagulation factors is treated with fresh blood. If a very low platelet content is present, platelet concentrates are given.

However, if a manifest consumption syndrome with decrease in coagulation factors and platelets can be shown to be present, the patient is treated with fresh blood and heparin. Trasylol can be used instead of heparin to augment the anti-fibrinolytic activity because Trasylol has been shown to exert anti-coagulant activity.

Acute cardiac failure with pulmonary oedema is sometimes seen in thoracic patients. We have made it a practice to intubate these patients and administer controlled ventilation with $100 \%$ oxygen. If the oedema is not immediately improved by this, a slight positive expiratory pressure is applied on the respirator. This pressure can be regulated according to the patient's circulatory condition and usually achieves a satisfactory result within a short period of time. The regular medical measures such as digitalization, infusion of hypertonic solutions, etc., are carried out as well.

Isoproterenol sulphate solutions are frequently used post-operatively in the cardiac patient, in whom a satisfactory cardiac output is not achieved by the afore-mentioned measures, and dilute solutions are employed (1-2 mg/1000 ml). Vasoconstrictors are only used if all other measures to improve the circulation have failed. However, good results have been achieved in isolated cases with diluted adrenaline solutions.

Acid-base balance is repeatedly followed from arterial samples. Respiratory acidosis is corrected by increased ventilation by the respirator and deficits in buffer base are compensated with $6 \%$ sodium bicarbonate solutions or THAM-buffer. The latter drug is frequently used during and after open-heart procedures and is always employed after cardiac arrest (Nahas, 1963). Changes of more than $3 \mathrm{mEq}$ in standard bicarbonate from pre-operative values are corrected.

\section{Control of body temperature}

An increase in body temperature may precipitate circulatory failure by the concomitant increase of oxygen consumption. This was the only obvious reason for respiratory failure in fifteen patients out of ninety-three who had normal chest radiographs and no previous signs of circulatory failure. Such failure was clinically evident when body temperature increased above $39^{\circ} \mathrm{C}$. Therefore, we try to keep the temperature around normal with either drugs (salicylates) or by physical means. The patients are placed on cooling mattresses through which a cold alcohol-water solution is circulated (Thermorite System). Shivering is controlled by the intravenous administration of opiates (morphine, pethidine) and phenothiazine derivatives of which chlorpromazine is most frequently used, in doses varying from 2.5 to $10 \mathrm{mg}$ i.v. each hour, depending on the effect on the circulation. A body temperature around $35^{\circ}$ is aimed at in severe cases, especially where lung function is so poor that gas exchange is not sufficient to adequately oxygenate the patient or to eliminate the carbon dioxide at increased temperatures. This has occasionally been seen in pre-operatively cyanotic patients, especially old Fallot's, who develop severe pulmonary changes with congestion and highly elevated ventilatory pressures on the 3 rd to 4th post-operative day. Prognosis is usually poor in such patients. 
Complete $A-V$ block is sometimes seen, either as a complication following surgery or more commonly in patients with Adam-Stokes attacks. They are treated with intracardiac electrodes, either inserted during surgery or placed intravenously from the jugular vein into the right ventricle. The latter technique is now used exclusively in our unit for acute patients and has given excellent immediate and long-term results (Lagergren \& Johansson, 1963).

\section{Prevention of infections}

The dangers of cross-infections in intensive care are well known. Therefore constant attention must be paid to hygiene of the unit, its equipment, locality and personnel. Our unit has a hygienic programme which functions satisfactorily in this respect without making the everyday work with the patients too difficult. Thus the personnel of the unit wear special clothes and are not allowed to leave the unit without a complete change except when they are going to the nearby operating-room area. Special foot-wear is worn and visiting doctors are required to change coats before entering the patient's room. Visits from relatives are limited and no regular visiting hours exist. Non-disposable instruments and equipment utilized in the room are left for $1 \mathrm{hr}$ in strong disinfectant solution (phenol-soap) and then brought to the cleaning area in sealed plastic bags. The isolation room has installations for steam-cleaning of bedpans and similar utensils. All floors are of plastic material and are welded without any crevices, so as to facilitate cleaning. Bacteriological cultures are done regularly from patient's equipment and localities.

\section{Cleaning of the respirators}

Respiratory equipment, unless properly cleaned and sterilized between use on patients, is a most dangerous source for the spread of infections. The following procedure is employed for the Engström respirator: Before the machine is brought out to the cleaning area, breathing tubes, connection pieces, etc., are placed in a solution of phenol-soap.* The respirator is cleaned on the outside with a $70 \%$ alcohol solution and the engine compartment with alcohol and white spirits. The standard humidifier is emptied and taken apart and the plastic sponge discarded. The humidifier is either steam-autoclaved (the stainless steel type) or boiled for a short period of time (the plastic material type). The patient valve is taken out and washed in $70 \%$ alcohol or exchanged in a case of severe infection. The dosage valve is dismantled and cleaned with alcohol. The water in the water safety-lock is drained and re-

\footnotetext{
*o-Phenyl-phenol-sodium, $22.5 \mathrm{~g}$; Sapo kalinus venalis, 8; tetracemintetra-sodium $40 \%, 4 \mathrm{~g}$; Spiritus denaturatus $11.5 \mathrm{~g}$ Aqua ad 1.000; with $50 \%$ water for $2 \mathrm{hr}$.
}

placed with fresh distilled water. The breathing bag $\frac{1}{\infty}$ is exchanged in a case of severe infection. Bacterio- $\stackrel{.}{.}$ logical cultures are made from the humidifier, dosage and patient valves and at other various sites of the machine and must be found negative before the machine can be used again. In practically every case the cultures have been negative after this procedure. Presently a new technique is being evaluated for a more rapid and easier sterilization of the respirator $\nRightarrow$ based on the use of the ultrasonic humidifier. The respirator is connected in such a way that the gases may be ventilated in a closed circuit with nitrogen, and $70 \%$ alcohol is nebulized into the circuit by the nebulizer for $1 \mathrm{hr}$ (Petersen et al., 1967). Different bacteriological tests have demonstrated this to be an efficient method, whereby all the inside parts of the machine in connection with the patient may be sterilized. Those tests are now under evaluation and it is our hope that in the future it should be possible to recommend the method for general use. No airfilters are used on our respirators. The risk of direct air contamination is considered low, as most of the patients are treated in isolation rooms with good ventilation.

\section{Patient material}

About 100 patients are treated yearly with tracheostomy and respirator. During the last year an increasing number of shorter treatments for $24-48 \mathrm{hr}$ with an endotracheal tube have been employed. The number and type of patients treated during the years 1962-65 is illustrated in Table 2.

An illustration as to how the resources of the unit are employed is given in the following case-report:

A 46-year-old woman was operated upon for the correction of an atrial septal defect and abnormal venous return with the aid of extracorporeal circulation and hypothermia to $32^{\circ}$. The patient exhibited atrial fibrillation for 6 months prior to operation and the heart size was $870 \mathrm{ml} / \mathrm{m}^{2}$. A left-to-right shunt of four times the systemic flow was present and the pressure in the pulmonary artery at rest was $45 \mathrm{mmHg}$. The working capacity was low, $200 \mathrm{kpm}$. The correction was without difficulties and the perfusion was uneventful. After the operation the patient was in good general condition, responded well and with an adequate spontaneous respiration. She was returned to the intensive care unit and was left with spontaneous breathing with 3 litres of $\underset{2}{q}$ oxygen through a nasal catheter. During the night 0 the patient started to bleed and altogether $2500 \mathrm{ml} \stackrel{\overparen{D}}{\overparen{D}}$ of blood drained from the mediastinum and peri- $\stackrel{\infty}{+}$ cardium. Blood pressure and circulation were good $T$ all the time, as the blood was replaced in amounts equal to the loss. Blood pressure fluctuated between 80 and $100 \mathrm{mmHg}$. Central venous pressure had been high since the end of operation-around 20$30 \mathrm{cmH}_{2} \mathrm{O}$-which at the time of operation was 
TABLE 2

Clinical material treated with respirator as related to type of intervention (1962-65)

\begin{tabular}{|c|c|c|c|c|c|c|c|c|c|c|c|c|c|c|}
\hline \multirow{3}{*}{ Operation } & \multicolumn{4}{|c|}{ Heart } & \multirow{2}{*}{\multicolumn{2}{|c|}{ Lungs }} & \multirow{2}{*}{\multicolumn{2}{|c|}{$\begin{array}{l}\text { Great } \\
\text { vessels }\end{array}$}} & \multirow{2}{*}{\multicolumn{2}{|c|}{$\begin{array}{l}\text { Oesophagus } \\
\text { Stomach }\end{array}$}} & \multirow{2}{*}{\multicolumn{2}{|c|}{$\begin{array}{l}\text { Other operations: } \\
\text { myasthenia gravis, } \\
\text { chest wall tumours, } \\
\text { mediastinal tumours }\end{array}$}} & \multirow{2}{*}{\multicolumn{2}{|c|}{$\begin{array}{l}\text { Non-surgical } \\
\text { interventions } \\
\text { chest injuries }\end{array}$}} \\
\hline & \multicolumn{2}{|c|}{ Open } & \multicolumn{2}{|c|}{ Closed } & & & & & & & & & & \\
\hline & No. & Deaths & No. & Deaths & No. & Deaths & No. & Deaths & No. & Deaths & No. & Deaths & No. & Deaths \\
\hline $\begin{array}{l}1962 \\
1963 \\
1964 \\
1965\end{array}$ & $\begin{array}{l}24 \\
38 \\
43 \\
44\end{array}$ & $\begin{array}{l}18 \\
19 \\
15 \\
10\end{array}$ & $\begin{array}{l}5 \\
9 \\
5 \\
7\end{array}$ & $\begin{array}{l}1 \\
1 \\
2 \\
3\end{array}$ & $\begin{array}{l}20 \\
22 \\
16 \\
17\end{array}$ & $\begin{array}{l}8 \\
8 \\
6 \\
2\end{array}$ & $\begin{array}{r}11 \\
6 \\
12 \\
11\end{array}$ & $\begin{array}{l}6 \\
3 \\
5 \\
4\end{array}$ & $\begin{array}{l}6 \\
8 \\
5 \\
7\end{array}$ & $\begin{array}{l}5 \\
7 \\
3 \\
5\end{array}$ & $\begin{array}{l}2 \\
3 \\
6 \\
3\end{array}$ & $\begin{array}{l}1 \\
0 \\
0 \\
0\end{array}$ & $\begin{array}{l}13 \\
12 \\
15 \\
14\end{array}$ & $\begin{array}{l}4 \\
1 \\
4 \\
3\end{array}$ \\
\hline $1962-65$ & 149 & 62 & 26 & 7 & 75 & 24 & 40 & 18 & 26 & 20 & 14 & 1 & 54 & 12 \\
\hline
\end{tabular}

Total number of patients treated 1962-65, 528; survivals, 384; deaths, 144.

thought to be due to a left superior vena cava and rather poor drainage at the point where the venous catheter had been inserted during the operation. Repeated chest X-rays during the night showed only a minimal enlargement of the mediastinal space. During the night urinary production decreased and altogether only about $400 \mathrm{ml}$ of urine had been passed since the end of the operation. Serum potassium increased during the night and the highest value encountered was $6.9 \mathrm{mEq}$. Resonium, administered repeatedly, decreased it to 4.9 in the early morning. A short period, less than $15-30 \mathrm{sec}$, of asystole occurred at 06.17 hours, but heart action resumed immediately on external massage. The circulation was still clinically satisfactory with an arterial blood pressure around $85-90 \mathrm{mmHg}$, venous pressure around $25 \mathrm{cmH}_{2} \mathrm{O}$ and a pulse frequency of 85-90. In order to improve her circulation, a very dilute isoproterenol drip was started which increased the pulse rate and blood pressure. An arterial blood sample at 07.30 hours showed a $\mathrm{PaO}_{2}$ of only $67 \mathrm{mmHg}$ in spite of a high flow of nasal oxygen. Hypertonic glucose was administered via the cava catheter. The diagnosis of the condition lay between left heart failure with oliguria as a complication of the pump-procedure and a cardiac tamponade. The latter diagnosis did not seem likely considering the chest X-rays and the relatively good circulation which could easily be maintained with the isoproterenol drip. A new arterial sample at $\mathbf{1 0 . 0 5}$ hours showed that metabolic acidosis had started to develop. She was given $120 \mathrm{mEq}$ of bicarbonate and $24 \mathrm{mEq}$ THAM-buffer during the next hours, which normalized the standard bicarbonate. In spite of a low arterial oxygen tension she was clinically in satisfactory condition, but it was decided to perform a tracheotomy. Two hours later she again had signs of metabolic acidosis, but oxygen tension was $103 \mathrm{mmHg}$. The tracheotomy was now performed under pethidine-oxygen-succinylcholine anaesthesia with an endotracheal tube. The blood pressure decreased at the end of the tracheotomy and the ECG, which was monitored the whole time, as well as the arterial blood pressure, showed an increasing bradycardia. This could be relieved after a few external compressions and increasing the rate of isoproterenol infusion. The patient was ventilated with the Engström respirator and the circulation improved. At 15.30 hours another short period of circulatory arrest occurred, again relieved after external massage but with the addition of $200 \mu \mathrm{g}$ of adrenaline in order to restore the circulation. $120 \mathrm{mEq}$ of THAM-buffer was given and the blood gas analysis $10 \mathrm{~min}$ later showed normal values. The patient was awake and responded well. However, at 16.05 hours a short arrest occurred again and it was then decided on to explore to rule out the possibility of a heart-tamponade. At induction of anaesthesia, which was made with $2 \mathrm{mg}$ of phenoperidine chloride and $6 \mathrm{mg}$ of D-tubocurare, the patient again had a cardiac arrest which was promptly treated with external massage during the time the patient was draped for surgery. The chest was opened and the circulation improved as soon as the pericardium was opened. Approximately $800 \mathrm{ml}$ of clotted blood were found around the heart, in the mediastinum and the right pleura. When this had been removed, the heart resumed good regular beating with a frequency of $80-90 / \mathrm{min}$. Blood pressure $90 / 60$, with a venous pressure of $10 \mathrm{cmH}_{2} \mathrm{O}$. An arterial sample taken at $\mathbf{1 7 . 0 0}$ hours during reoperation indicated a severe metabolic acidosis, normal $\mathrm{PaCO}_{2}$ and an oxygen tension of $127 \mathrm{mmHg}$. The patient was given $90 \mathrm{mEq}$ of bicarbonate rapidly within a period of $10 \mathrm{~min}$, as it was noticed that urine production had started again with a good flow during the operation. The clots were evacuated and a temporary pace-maker electrode was inserted into the myocardium and connected to an external pacemaker at a frequency of $90 / \mathrm{min}$. Isoproterenol was discontinued. It was noticed that slight continuous bleeding occurred from the right ventricle from the 
site of a needle puncture at the time of operation for pressure measurements. This probably explained the blood loss during the night after the operation, as no other bleeding points could be observed. The patient was maintained on the respirator for the next 8 days, as she exhibited signs of left heart failure with radiological signs of pulmonary congestion and slight peripheral oedema. The urinary output became normal immediately after re-operation and remained around $1200 \mathrm{ml}$ daily. The pacemaker was disconnected after 8 days and the final recovery was uneventful.

This report illustrates a common aspect of the problems of thoracic intensive care. We have a patient with impaired cardiac function after a major corrective procedure with post-operative bleeding and oliguria. The problem has many facets, diagnostic as well as therapeutic. The constant supervision of the patient with adequate monitoring of ECG, blood pressure and blood-gases, besides $\mathrm{X}$-rays, etc., made it possible to carry the patient through a critical period when the diagnosis was not clear. However, looking retrospectively at the casehistory, it is evident that the thoracic 'rule of thumb', that a blood-loss of more than $1500 \mathrm{ml}$, even if it can be replaced and circulatory function satisfactorily maintained, is usually a strong indication for a surgical re-exploration, is a valid one. The respirator treatment illustrates how the patient could be relieved of the respiratory work and guaranteed optimal blood gas tensions under the prevailing circumstances. Without the respirator it would have been rather difficult to compensate for the severe changes in metabolic acidosis brought about by a failing peripheral circulation, oliguria and decreased venous and tissue oxygen tension. It also demonstrates that when tracheotomy is performed in such a patient the risk of an acute deterioration of circulation during the procedure is great and adequate monitoring must be available. In this case we waited too long before the tracheotomy was made, a delay which in this particular case was due to other technical reasons. It is interesting to note how rapidly the metabolic acidosis developed after even short periods of cardiac arrest, adequately treated with external massage. This indicates that buffers like THAM and bicarbonate should be used in the acute treatment even without previous analysis of blood gases and acid-base balance.

\section{Acknowledgments}

The authors wish to express their gratitude to Mrs A. Linneroth, Department of Hospital Planning, Karolinska Sjukhuset, for her efforts and ideas in planning of the Intensive Care Unit, Thoracic Clinics, and to Dr P. Ohlsson,
Associate Professor, Department of Thoracic Surgery, for the view-points on bleeding and coagulation problems post-operatively.

\section{References}

BJöRK, V.O. \& ENGSTRöM, C.-G. (1955) The treatment of ventilatory insufficiency after pulmonary resection with tracheotomy and prolonged artificial ventilation.J. thorac. Surg. 30, 356.

BJÖRK, V.O. and GRENVIK, Å. (1967) Percutaneous intracardiac catheters for postoperative observations in thoracic surgery. J. Cardiovasc. Surg. (In press).

CRAFOORD, C.L. (1938) On the technique of pneumonectomy in man. Acta chir. scand. Suppl. 54.

Dammann, J.F., JR, Thung, N., Christlieb, I.I., LittleFIELD, J.B. \& MUlleR, W.H. (1963) The management of the severely ill patient after open-heart surgery. J. thorac. cardiovasc. Surg. 45, 80.

ENGSTRöm, C.-G. (1963) The clinical application of prolonged controlled ventilation. With special reference to a method developed by the author. Acta anaesth. scand. Suppl. XIII.

Engström, C.-G. \& Herzog, P. (1959) Ventilation nomogram for practical use with the Engström respirator. Acta chir. scand. 245, 37, Suppl.

EngStröm, C.-G., Herzog, P. \& Norlander, O.P. (1961) A method for the continuous measurement of oxygen consumption in the presence of inert gases during controlled ventilation. Acta anaesth. scand. 5, 115.

Freeman, J. \& NunN, J.F. (1963) Ventilation perfusion relationships after haemorrhage. Clin. Sci. 24, 135.

GAY, L.N. \& LONG, J.S. (1949) Clinical evaluation of isopropylepinephrine in management of bronchial asthma. J. Amer. med. Ass. 139, 452.

GordH, T., Linderholm, H. \& NoRlander, O.P. (1958) Pulmonary function in relation to anaesthesia and surgery evaluated by analysis of oxygen tension of arterial blood. Acta anaesth. scand. 2, 15.

Grenvik, $\AA$. (1966) Respiratory, circulatory and metabolic effects of respirator treatment. A clinical study in postoperative thoracic surgical patients. Acta anaesth. scand., Suppl. XIX.

Hedley-Whyte, J., Corning, H., Laver, M.B., Austen, W.G. \& BENDIXEN, H. (1965) Pulmonary ventilation perfusion relations after heart valve replacement or repair in man. J. clin. Invest. 44, 406.

Herzog, P., Engström, C.-G. \& Norlander, O.P. (1964) Ultra-sonic generation of aerosol for the humidification of 3 inspired gas during volume-controlled ventilation. Acta anaesth. scand. 8, 75.

LAGERGREN, H. \& JoHANSSON, L. (1963) Intracardiac stimulation for complete heart block. Acta chir. scand. 125, 562 .

NaHAS, G. (1963) The clinical pharmacology of THAM. Clin. Pharmacol. 4, 784.

Norlander, O.P., BJörk, V.O., Crafoord, Cl., Friberg, 兰. O., Holmdahl, M., Svensson, A. \& Wildman, B. (1961) N Controlled ventilation in medical practice. Anesthesia, o 16, 285.

Petersen, N.O.A., Engström, C.-G., Herzog, P., \& $\mathrm{N}$ NORLANDER, O.P. (1967) Ultra-sonic sterilization of $\omega$ respirators with $70 \%$ alcohol and nitrogen. Preliminary report (To be published).

Sabar, E.F., Norlander, O.P., Osborn, J.J. \& Gerbode, F. (1965) Gas distribution studies in experimental unilateral $\&$ bronchial constriction using an accelerating, volumecontrolled respirator. Surgery, 58, 713.

ThunG, N. \& Norlander, O.P. (1960) Cardio-respiratory changes during anaesthesia for open-heart surgery. Acta anaesth. scand. 10, 79. 


\section{Errata}

Postgraduate Medical Journal (1967) Vol. 43, No. 498, 'Intensive Therapy.'

Please nOte the following:

Page 222. The last sentence of the first paragraph should read: 'During hypotension a metabolic acidosis was found in all patients but the base deficit showed no correlation with the concentrations of lactate. There was statistical correlation with $\Delta \mathrm{L} / \mathrm{P} \%$.'

Page 223. The last sentence of paragraph (b) should read: 'Hypotension responded ....'

Page 254. The legend to Fig. A7 should read:

-Pressure-volume loops from the second case when breathing spontaneously $\left(A_{1}\right)$ and during controlled IPPV (B). A normal loop (A) is shown for comparison.

Page 268. The formula in the second column should read:

$$
\frac{\mathrm{Q}}{\mathrm{Qs}} \cdots \frac{1}{1+\frac{(\mathrm{A}-\mathrm{V} \text { diff }) \times 330}{\mathrm{PAO}_{2}-\mathrm{PaO}_{2}}}
$$




\section{Errata}

Postgraduate Medical Journal (1967) Vol. 43, No: 498, 'Intensive Therapy.'

Please note the following:

Page 222. The last sentence of the first paragraph should read: 'During hypotension a metabolic acidosis was found in all patients but the base deficit showed no correlation with the concentrations of lactate. There was statistical correlation with $\Delta \mathrm{L} / \mathrm{P} \%$,'

Page 223. The last sentence of paragraph (b) should read:

'Hypotension responded ....'

Page 254. The legend to Fig. A7 should read:

'Pressure-volume loops from the second case when breathing spontaneously $\left(\mathrm{A}_{1}\right)$ and during controlled IPPV (B). A normal loop (A) is shown for comparison.

Page 268. The formula in the second column should read:

$$
\frac{\mathrm{Q}}{\mathrm{Qs}}=\frac{1}{1+\frac{(\mathrm{A}-\mathrm{V} \text { diff }) \times 330}{\mathrm{PAO}_{2}-\mathrm{PaO}_{2}}}
$$

